\title{
Effective engagement and involvement with community stakeholders in the co-production of global health research
}

\author{
Doreen Tembo and colleagues argue that small changes as well as larger system-wide changes \\ can strengthen citizens' contribution to knowledge in health research
}

I nvolving a broad range of individual and collective perspectives in global health research outside of academic research is gaining increasing recognition as a mechanism for achieving a greater impact. This activity goes by many names (box 1). In the global north or a high income country, it is commonly called "patient and public involvement," "engagement," or "participation.” In low and middle income countries or the global south, these participatory processes are termed "community engagement," "participation," and "community engagement and involvement." ${ }^{1-3}$ Co-production, a core feature of community engagement and involvement, is common to health research in both the global north and south, with a range of potential benefits. It helps to ensure that health research contributes to building knowledge and generating innovations that benefit users of research. ${ }^{4}$ For research that drives change and reduces the waste of resources, ${ }^{5}$ co-production should start

\section{KEY MESSAGES}

- Co-production of research is key to achieving more equal relationships in global health research and to delivering positive benefits to a wide range of stakeholders

- Co-production requires investment in time and resources and a commitment to building trust between researchers and communities

- To deal with the power imbalance between researchers and communities, and within research collaborations, it is important to include experiential knowledge and participatory methodologies

- Global health research funders and institutions based in the global north can better support co-production by embedding best practices in their funding criteria and systems for career progression and reward from the earliest stages, when problems are identified and priorities defined. ${ }^{6}$ Such an approach supports research that is ethical, specific, and appropriate to the local community. ${ }^{7-12}$ Involvement of end users in the design of projects has also been shown to improve recruitment of participants and research methods, making implementation and the impact of the research results more likely. $^{913}$

Various challenges exist to the effective adoption of co-production in global health research. ${ }^{17} 18$ There can be no one size fits all approach. Nevertheless, there are some common challenges and enablers related to citizen centred co-production. These barriers and facilitators when co-producing research, centre on problems of politics, finance and resourcing, access and inclusion, relationship building, and community disengagement (table 1). We will refer to these challenges and enablers when we discuss the co-production principles in the following section.

The UK National Institute for Health Research (NIHR) co-production guidance and the closely related Unicef Minimum Standards for Community Engagement ${ }^{1619}$ (table 2) provide best practice guidance for research teams to navigate these key common challenges and enablers. In addition to step changes, which can be made by adopting the principles of power sharing, building relationships, acknowledging diverse perspectives, reciprocity, and respecting different knowledge bases, structural changes are also needed to better embed co-production in global health research.

\section{Sharing power}

Sharing power is a key facet of co-production (table 2). Global health research is shaped by power asymmetries or imbalances between funding bodies, research institutions, professional bodies, policy makers, and communities. ${ }^{20}$ The exercise of power often depends on who has the resources, the decision making power, and knowledge. These power dynamics and inequalities depend on whose knowledge is valued in interactions both within research teams, and between those teams and the communities with whom they engage. ${ }^{2122}$ A co-production framework seeks to redistribute knowledge based power and replace it with mutual learning between all participants in a collaboration.

Because such approaches to research are still new and may cause uneasiness among both researchers and communities, it is the responsibility of research teams to create mutual adaptive learning processes, thus allowing research questions and designs or plans to be amended. Such changes depend on emerging learning and skills building, and ensure researchers include divergent perspectives in their research. ${ }^{23}$ Communities, on the other hand, can act alone by using existing constitutional and institutional structures to lobby for more power and influence within the co-production processes. ${ }^{24}$ When such structures do not exist, or when there is political interference, researchers can work with local leaders and political stakeholders to identify and build on local priorities. The Sonagachi project in Kolkata, India is a good example of aligning project priorities with the priorities of those in power (local politicians) and involving local gatekeepers as project team members, to access, involve, and ultimately empower marginalised female sex workers. ${ }^{25}$

Some funders and organisations, such as the Canadian International Development Research Centre and the UK NIHR, use mechanisms to level out power differentials in global health research. Their methods include supporting communities and civil society, such as non-governmental, user led, or community based organisations, by providing flexible budgets or funding, which communities and user groups can use to ensure culturally appropriate and user led research design and practice. The World Health Organization Special Programme for Research and Training in 


\section{Box 1: Terminology for partnering with communities}

Many terms are used to describe how researchers form partnerships with non-academic communities. The lack of universally agreed and defined terms can lead to a lack of clarity about shared values and scope of activities, and relevance to other researchers and communities. It can also hamper discovery and synthesis of evidence from the literature. The UK National Institute for Health Research (NIHR) distinguishes between terminologies by defining involvement as an active partnership with patients and the public, participation as participants providing data for research, and engagement as researchers sharing research outputs with stakeholders, including patients. ${ }^{14}$ Internationally these terms are generally used interchangeably, and other terms, such as user or consumer involvement and citizen participation, are also used. In the context of global health, community engagement encompasses many different levels of the consultation-collaboration/partnership/ co-production-control continuum of involvement. ${ }^{15}$ Organisations such as Unicef, however, use the term community participation in a similar way to patient and public involvement, to indicate a more active form of partnership with communities. ${ }^{16}$ The NIHR has adopted the term community engagement and involvement to encompass the full spectrum and levels of partnership with communities. ${ }^{2}$

Tropical Diseases "Malaria and bilharzia in southern Africa” study, for example, demonstrates how communities were encouraged to set up community advisory boards, which were given funding to cover research costs for community engagement. ${ }^{25}$

\section{Building and maintaining relationships}

Building relationships of trust with communities is a time, resource, and labour intensive process. ${ }^{2627}$ Key facets of building sustainability and trust include establishing responsive mutual communication with communities and building capacity for research by encouraging participatory approaches, such as citizen science. An example of a programme which builds local research and community capacity is the Kenya Medical Research Institute Wellcome Trust research programme in Kilifi, which works to build up familiarity with research in the surrounding communities, and involve them in various projects. ${ }^{28}$

Much research funding is limited to five years or less, resulting in involvement of communities on a project by project basis instead of developing long term relationships with researchers. Encounters are often transactional and focus on getting a project completed. Such short term interactions, especially if there is no lasting benefit to the community, can be counterproductive or exploitative, ${ }^{29}$ leading to community disengagement, especially if researchers do not share their results. ${ }^{3031}$ Future researchers wishing to engage these communities will need to determine why they are disengaged and work with them to develop joint research.

Although some research centres in the UK successfully build relationships with communities, it is more usual for researchers to recruit a small group of people who can provide insights from their own experience. ${ }^{32-34}$ When views of the community are sought, a representative from a civil society organisation is sometimes involved. This approach saves time and cost, but presents only one perspective on research. ${ }^{35}$ When such a representative is necessary-for example, on a funding or ethics committee, it is crucial to ensure that the concerns of marginalised groups are included, by regular meetings with them. For example, the NIHR piloted a community of practice of public members who discussed what research should be prioritised, with a rotating representative from this community attending the prioritisation committee. The pilot was evaluated by NIHR and learning was shared and discussed with the community of practice members.

Research organisations have a key role in ensuring that the development of relationships with communities, and civil society organisations more broadly, becomes a valued, and professionally rewarded academic activity. ${ }^{36} 37$ For example, some universities have introduced community engagement and involvement as a criterion for career progression. ${ }^{38}$ Effective communication of opportunities for community members to learn more about research into their health condition, and building their research and professional skills, contributes to community engagement.

\section{Including all perspectives and skills}

A major concern for health research is that educated older, often retired, middle class

\begin{tabular}{|c|c|c|}
\hline \multirow[b]{2}{*}{ Theme } & \multicolumn{2}{|r|}{ Element } \\
\hline & Challenges & Enablers \\
\hline Politics & $\begin{array}{l}\text { Political interference and unpredictable political situations } \\
\text { necessitating a hold or delay for project work }\end{array}$ & $\begin{array}{l}\text { Using established political structures without being partisan, } \\
\text { building on local political agendas }\end{array}$ \\
\hline $\begin{array}{l}\text { Finance and } \\
\text { resourcing }\end{array}$ & Insufficient and rigid project budgets, and undue bureaucracy & $\begin{array}{l}\text { Clear and itemised budget to facilitate co-production } \\
\text { Flexible budgets which can deal with unpredictable costings associated with } \\
\text { co-production/participatory action research-agreed before funder approvals }\end{array}$ \\
\hline $\begin{array}{l}\text { Access and } \\
\text { inclusion }\end{array}$ & $\begin{array}{l}\text { Inability to engage or access communities and pushing ideas } \\
\text { onto communities without understanding their problems and } \\
\text { needs }\end{array}$ & $\begin{array}{l}\text { Being open minded, flexible, and inclusive in using co-developed solutions } \\
\text { Taking time to build trust and facilitate mutual learning Learning lessons } \\
\text { from existing or previous projects in the area and understanding community } \\
\text { perspectives and their real problems }\end{array}$ \\
\hline $\begin{array}{l}\text { Relationship } \\
\text { building }\end{array}$ & $\begin{array}{l}\text { Transactional interactions with the community } \\
\text { Unfamiliarity with, and disrespect for, local culture and norms } \\
\text { Funding and reward mechanisms that don't focus on } \\
\text { development of a sustainable relationship, and community } \\
\text { memories of poor research experiences }\end{array}$ & $\begin{array}{l}\text { Allowing time for developing relationships with the community and } \\
\text { communication mechanisms } \\
\text { Working with communities that have been involved in building relationships } \\
\text { Where appropriate, harnessing the cultural elements that will better enable } \\
\text { engagement with communities, such as the welcoming nature of communities-for } \\
\text { example, Ubuntu philosophy in Africa } \\
\text { Involving local communities and user led organisations from the start }\end{array}$ \\
\hline Disengage-ment & $\begin{array}{l}\text { Uncompromising, resistant, or distrustful communities } \\
\text { High or unrealistic standards or expectations which might } \\
\text { have been influenced by unfulfilled promises from preceding } \\
\text { research teams }\end{array}$ & $\begin{array}{l}\text { Developing understanding of the causes of resistance and mistrust } \\
\text { Not ignoring community expectations no matter how seemingly } \\
\text { unreasonable and deviating from one's project }\end{array}$ \\
\hline
\end{tabular}




\begin{tabular}{|c|c|}
\hline NIHR Involve co-production principles & Related Unicef minimum standards for community engagemen ${ }^{\text {t* }}$ \\
\hline $\begin{array}{l}\text { Sharing of power-the research is jointly } \\
\text { owned and people work together to } \\
\text { achieve a joint understanding }\end{array}$ & $\begin{array}{l}\text { Adaptability and localisation: approaches are developed based on local contexts. They should be flexible and } \\
\text { responsive to local needs, conditions, and concerns. Flexible community engagement approaches ensure adaptation } \\
\text { to new circumstances, deal with sudden or unexpected changes, and respond to uncertainty } \\
\text { Participation: communities assess their own needs and participate in the analysis, planning, design, implementation, } \\
\text { monitoring, and evaluation of governance, development, and humanitarian initiatives. Community views and needs are } \\
\text { given due weight in all of the above }\end{array}$ \\
\hline Building and maintaining relationships & $\begin{array}{l}\text { Communication: communities give and receive clear, appropriate, and accurate information through two } \\
\text { way communication } \\
\text { Building on local capacity: build on the existing skills and resources of communities and the local groups and } \\
\text { organisations that serve them }\end{array}$ \\
\hline $\begin{array}{l}\text { Including all perspectives and skills- the } \\
\text { researchers should include all those who } \\
\text { can make a contribution }\end{array}$ & $\begin{array}{l}\text { Inclusion: include community members and groups that are under-represented, disadvantaged, vulnerable, } \\
\text { and marginalised }\end{array}$ \\
\hline $\begin{array}{l}\text { Respecting and valuing the knowledge of } \\
\text { everyone involved in the research }\end{array}$ & $\begin{array}{l}\text { Participation: communities assess their own needs and participate in the analysis, planning, design, implementation, } \\
\text { monitoring, and evaluation of governance, development, and humanitarian initiatives. Community views and needs are } \\
\text { given due weight in all of the above }\end{array}$ \\
\hline $\begin{array}{l}\text { Reciprocity, so everybody benefits from } \\
\text { working together }\end{array}$ & $\begin{array}{l}\text { Empowerment and ownership: communities have opportunities to own and feel empowered by community engagement } \\
\text { processes }\end{array}$ \\
\hline
\end{tabular}

individuals, or more organised groups are most likely to be involved. Co-production becomes more inclusive when a plan is established for dealing with communities in culturally acceptable ways, taking into account local needs and capabilities. The research team needs to identify and communicate with all relevant stakeholders, including vulnerable and marginalised groups. ${ }^{39}$ Such approaches will minimise resistance, distrust, and unrealistic expectations from the community.

A specialist with knowledge of co-production processes will always be needed within health research teams. Many funders advocate transdisciplinary research teams so that together with the usual disciplines, such as clinical or public health research, epidemiology, health economics, and statistics, a broader range of social sciences, humanities, nonacademic disciplines, and communities are also included..$^{40}$ For example, the research team for the Malaria and Bilharzia in Southern Africa (Mabisa) study had diverse disciplinary backgrounds, including nonacademic members. Community members used their knowledge of the local area to assist scientists in generating sophisticated maps, which acted as a starting point for designing environmental adaptation strategies for reducing vulnerabilities to vectorborne diseases. ${ }^{40}$ The inclusion of such expertise will ensure that the cultural and societal factors that might influence the (dis)engagement of communities are taken into account. Nevertheless, to ensure culturally appropriate community engagement, all members of a research team should be trained to carry this out.

Researchers need to be mindful of the jargon sometimes used in academia and health and how it can create barriers to collaboration. Meeting places that are welcoming to all should be used. Community members might not feel comfortable meeting in institutional environments, which might exacerbate the power imbalance between communities and academics or professionals. A positive consequence of the current coronavirus pandemic has been "digital democratisation"-the ability to allow people to co-produce research regardless of location, albeit subject to the availability of equipment and connectivity. That said, we also recognise that some people are digitally excluded, and researchers need to find ways of bridging this divide.

\section{Reciprocity and respecting and valuing different knowledge bases}

Reciprocity is essential to co-produced research. ${ }^{41}$ Funders of global health research need to reconsider the rewards and impact of co-production. ${ }^{37}{ }^{42} \mathrm{Com}$ munities which devote their time, effort, and knowledge to shaping a research study should determine what benefits they receive and should be empowered by the processes. For example, benefits that empower communities might range from remuneration, skills training with certificates, access to research institution facilities, learning more about research and particular health conditions, and networking. The community can also be involved in determining what outputs of research are produced. Thus, the community might favour dissemination through methods such as plays, puppet shows, or comics, rather than purely through peer reviewed papers. The Planet DIVOC-91 comic is a key example of how the researchers worked with youth and other community stakeholders in low and middle income countries to provide information about covid-19 and research. ${ }^{43}$

Methodological hierarchies in global health research tend to favour quantitative rather than qualitative approaches, and yet it is qualitative approaches that often are used. ${ }^{44}$ Furthermore, experiential knowledge continues to be considered anecdotal, while the values of expert knowledge are increased within health research. Research teams need to place equal value on different types of knowledge, particularly the lived experiences and contextually specific knowledge of community partners. ${ }^{37}$

The funders of most global health research do not yet mandate community engagement and involvement, despite the plethora of guidance to enable researchers to achieve co-production. ${ }^{4647}$ A number of funders, including NIHR, insist on community engagement and involvement in research proposals and consider it a key criterion for funding. This approach might lead to a generational shift in the global health sector, making co-production the norm.

\section{Where we can go from here: recommendations for action}

Radical action is needed to embed coproduction. It is worrying that during the current pandemic, the level of community engagement and involvement has reduced despite clear guidance on how to carry out ethical and valuable work in an emergency. ${ }^{4849}$ This illustrates the tenuous position of co-production. ${ }^{50}$ Within emergency responses, co-production can be achieved by setting up rapid response community 


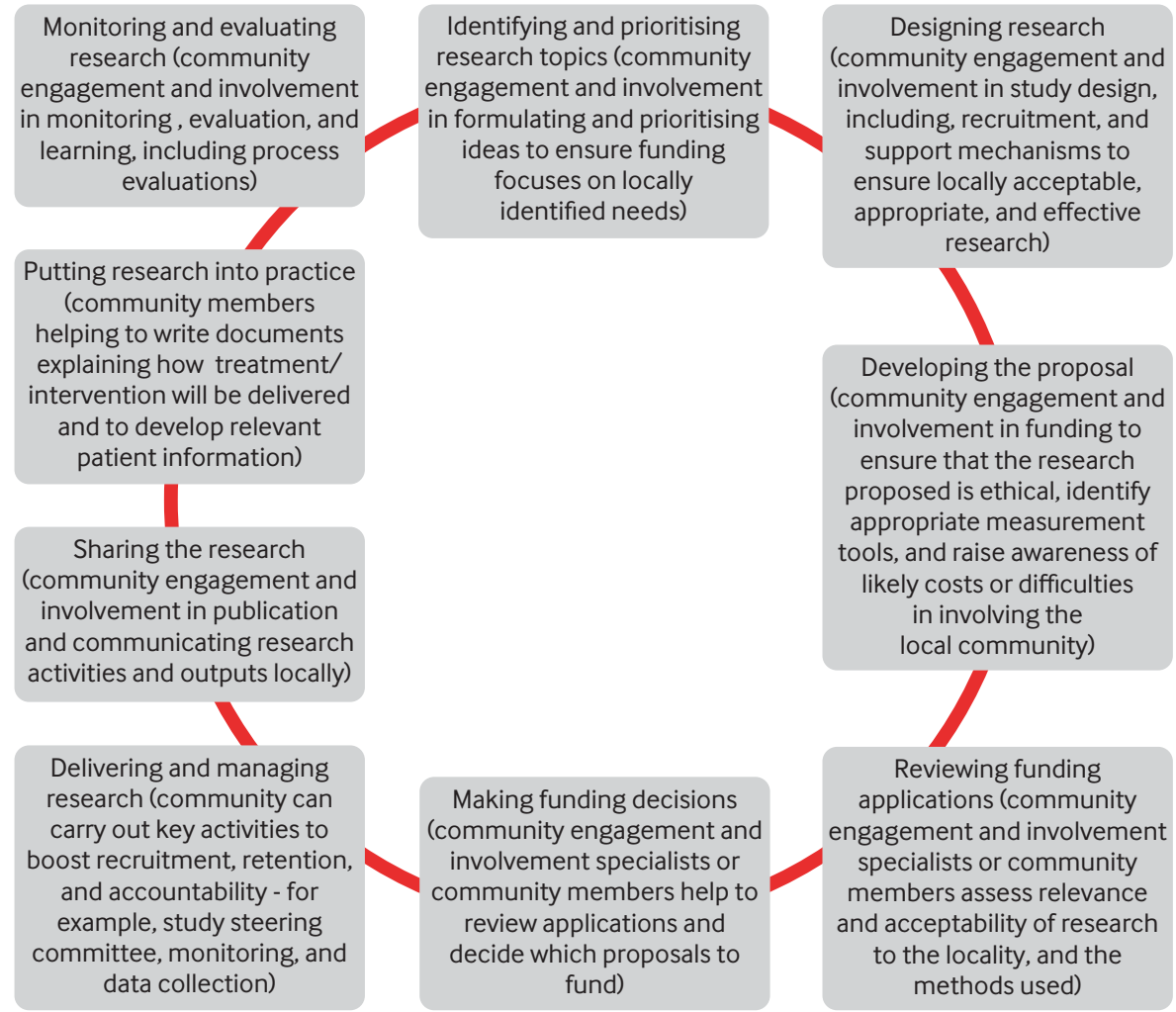

Fig 1 | Points of influence for co-production

panels, strengthening existing community relationships, and developing contingency plans for alternative methods of engagement during future outbreaks.

By expanding current practice and recognising the fundamental change in research culture that is required, leaders, funders, and institutions can do much to raise the profile, and demonstrate the effect, of co-production. They can recommend, or even better, mandate co-production of research, and develop mechanisms to make funding directly available to civil sector organisations. ${ }^{51}$ As discussed, reward mechanisms should be determined together with communities, and research ethics frameworks need to be more flexible to allow communities to be fairly paid for their involvement.

Funders and researchers also need to ensure that research priorities are determined with or by communities, are culturally appropriate and adapted to local settings, and that a wide range of community members are involved throughout the research process. Figure 1, adapted from an NIHR course for public reviewing, ${ }^{52}$ shows the various stages in the research process, from identifying and prioritising research through to monitoring and evaluating research, and the ways in which communities can be involved at each stage.
Academic journals can follow the lead of The BMJ, the NIHR Journals Library, and others, which require reporting on patient and public involvement. Journals could encourage the publication of research results on co-production, including the use of new methodological approaches, or by encouraging co-authorship by nonacademic community members.

To achieve change, we need to think internationally about how the quality of research in universities and in health ecosystems in the global north and south is assessed. In the UK, the Research Excellence Framework is the mechanism whereby the impact of universities' research is assessed, forming the basis for the allocation of funding. ${ }^{53}$ This framework could incorporate a mechanism that values and rewards the outputs of co-production (for example, the total number of peer reviewed articles that are single authorship or lead authored with community partners; evaluating how the research contributed to strengthening local community participation, skills building, research literacy, or creative engagement) and measures the effect of research on people's lives.

Universities can better align their reward and recognition mechanisms to encourage co-production. Academia and research funders also need to value transdisciplinary and team science, and the inclusion of skills that foster co-production. The curriculums for research methods need to embed the development of knowledge and skills for co-production.

Currently, government use of science and evidence in responding to the pandemic, and the spread of disinformation and mistrust, is being debated globally. ${ }^{54}$ Citizens and communities increasingly disseminate knowledge. On the one hand, the pandemic has uncovered underlying systemic health and socioeconomic inequities and, on the other, created a new set of possibilities for global health research that decentralises power and values co-production.

We thank the UK National Institute for Health Research (NIHR) and Department of Health and Social Care staff who provided input into the paper based on their personal views. These included Katalin Torok, senior research manager for patient and public involvement and engagement, UK NIHR; Patrick Wilson, head of global health communications and stakeholder engagement, UK NIHR; and Aaronjay Tidball, global health research programme officer, science, research and evidence directorate, Department of Health and Social Care, UK). We are also grateful to Pippa Coutts, policy and development manager, Carnegie Trust, UK, who was also involved in the roundtable discussion which informs this paper. The roundtable focused on approaches and challenges when engaging end users in the co-production of global health research.

Contributors and sources:DT and GH co-wrote the article, and collaborated on the production of the UK NIHR guidance on co-producing a research 
project, and practical resources demonstrating how research can be co-produced. DT and GH have facilitated several co-production events, which have all involved public contributors. The paper draws on the discussions at these co-production events and the expert and experiential knowledge of all the authors, who also participated in these events. All authors contributed to, and commented on, this article.

Competing interests: We have read and understood BMJ policy on declaration of interests and declare: SS sits on the editorial board of this series of articles on co-production of knowledge in health research. She is part funded by NIHR Applied Research Collaboration, West Midlands; NIHR Health Protection Research Unit in gastrointestinal infections; and NIHR Health Protection Research Unit in genomics and enabling data. SS will not be involved in the editorial processes for this paper.

Patient and public involvement: Patients and members of the public have been involved in two roundtable events and in a conference that discussed co-production enablers and barriers from which we draw the data for this article. PB, DC, TC, and UR provide patient, public, and community voices from a high income country and POE from a low and middle income country. They were invited based on their history of involvement in health and social care research, and PE, for his involvement in development work in low and middle income countries. TC is a coauthor of the NIHR guidelines on co-production.

Provenance and peer review: Commissioned; externally peer reviewed.

This article is part of a series produced in conjunction with the WHO and the Alliance for Health Policy Systems and Research with funding from the Doris Duke Charitable Foundation. The BMJ peer reviewed, edited, and made the decision to publish.

Doreen Tembo, senior research manager patient and public involvement and external review ${ }^{1}$

Gary Hickey, senior public involvement manager ${ }^{1,2}$ Cristian Montenegro, assistant professor ${ }^{3}$

David Chandler, chief executive ${ }^{4}$

Erica Nelson, research fellow ${ }^{5}$

Katie Porter, assistant research manager, patient and public involvement ${ }^{1}$

Lisa Dikomitis, professor of anthropology and sociology of health ${ }^{6}$

Mary Chambers, head of public engagement with science $^{7,8}$

Moses Chimbari, professor of public health ${ }^{9}$ Noni Mumba, head of community engagement ${ }^{10}$ Peter Beresford, emeritus professor of citizen participation ${ }^{11}$

Peter 0 Ekiikina, public contributor low and middle income countries ${ }^{12}$

Rosemary Musesengwa, senior researcher ${ }^{13}$

Sophie Staniszewska, professor of health research (patient and public involvement and experiences of (are) $)^{14}$

Tina Coldham, public adviser and research fellow ${ }^{15,16}$ Una Rennard, public contributor to health and social care research $^{17}$

${ }^{1}$ Wessex Institute, Faculty of Medicine, University of Southampton, Southampton, UK

${ }^{2}$ School of Health Sciences, University of Brighton, Brighton, UK

${ }^{3}$ School of Nursing, Pontificia Universidad Católica de Chile, Santiago, Chile

${ }^{4}$ The Psoriasis and Psoriatic Arthritis Alliance, St Albans, Hertfordshire, UK

${ }^{5}$ London School of Hygiene and Tropical Medicine, London, UK
${ }^{6}$ School of Medicine, Keele University, Staffordshire, UK

${ }^{7}$ Oxford University Clinical Research Unit, Vietnam

${ }^{8}$ Tropical Medicine and Global Health, Nuffield Department of Medicine, University of Oxford, UK

'University of KwaZulu-Natal, School of Nursing and Public Health, South Africa

${ }^{10}$ KEMRI Wellcome Trust Research Programme, Nuffield Department of Medicine, Centre for Tropical Medicine and Global Health, University of Oxford, Kenya

${ }^{11} \mathrm{School}$ of Health and Social Care, University of Essex, Colchester, UK

${ }^{12}$ Foundation for Open Development, Tororo, Uganda ${ }^{13}$ Department of Psychiatry, University of Oxford, Oxford, UK

${ }^{14}$ Warwick Medical School, Division of Health Sciences, University of Warwick, Coventry, UK

${ }^{15}$ National Institute for Health Research Centre for Engagement and Dissemination, London, UK

${ }^{16}$ School for Social Care Research, National Institute Health Research, London, UK

${ }^{17}$ Oxfordshire, UK

Correspondence to: D Tembo d.tembo@soton.ac.uk

\section{(c) (i) (8)} OPEN ACCESS

This is an Open Access article distributed under the terms of the Creative Commons Attribution IGO License (https://creativecommons.org/licenses/ by-nc/3.0/igo/), which permits use, distribution, and reproduction for non-commercial purposes in any medium, provided the original work is properly cited.

\section{Check for updates}

1 Vasquez EE, Perez-Brumer A, Parker RG. Social inequities and contemporary struggles for collective health in Latin America. Glob Public Health 2019;14:777-90. doi:10.1080/17441692.2019.1 601752

2 Nelson E. A resource guide for community engagement and involvement in global health research. The Institute of Development Studies and National Institute for Health Research, 2019.

3 Tindana PO, Singh JA, Tracy CS, et al. Grand challenges in global health: community engagement in research in developing countries. PLoS Med 2007;4:e273. doi:10.1371/journal.pmed.0040273

4 Shaping Our Lives. A national network of service users and disabled people. 2020. https://www. shapingourlives.org.uk/resources/our-resources/ all-publications/co-production-what-is-it-guidelinesand-tips.

5 Glasziou P, Chalmers I. Research waste is still a scandal-an essay by Paul Glasziou and lain Chalmers. BMJ 2018;363:k4645. doi:10.1136/bmj.k4645

6 Tembo D, Morrow E, Worswick L, Lennard D. Is co-production just a pipe dream for applied health research commissioning? An exploratory literature review. Front Sociol 2019. doi:10.3389/ fsoc.2019.00050

7 Domecq JP, Prutsky G, Elraiyah T, et al. Patient engagement in research: a systematic review. BMC Health Serv Res 2014;14:89. doi:10.1186/14726963-14-89

8 Brett J, Staniszewska S, Mockford C, et al. Mapping the impact of patient and public involvement on health and social care research: a systematic review. Health Expect 2014;17:637-50. doi:10.1111/ j.1369-7625.2012.00795.x

9 Staley K. 'Is it worth doing?' Measuring the impact of patient and public involvement in research. Res
Involv Engagem 2015;1:6. doi:10.1186/s40900015-0008-5

10 Carr S. Position paper: Are mainstream mental health services ready to progress transformative co-production? National Development Team for Inclusion, 2016.

11 Lignou S, Capitao L, Hamer-Hunt JM, Singh I. Co-production: an ethical model for mental health research?Am J Bioeth 2019;19:49-51. doi:10.1080/ 15265161.2019.1619877

12 Adhikari B, Pell C, Cheah PY. Community engagement and ethical global health research. Glob Bioeth 2019;31:1-12. doi:10.1080/11287462.201 9.1703504

13 Crocker JC, Ricci-Cabello I, Parker A, et al. Impact of patient and public involvement on enrolment and retention in clinical trials: systematic review and meta-analysis. BMJ 2018;363:k4738. doi:10.1136/ bmj.k4738

14 INVOLVE. Briefing notes for researchers: involving the public in NHS, public health and social care research. Eastleigh: INVOLVE; 2012. https://www.invo.org.uk/ wp-content/uploads/2014/11/9938_INVOLVE_ Briefing_Notes_WEB.pdf.

15 Arnstein SR. A ladder of citizen participation J Am Inst Plann 1969;35:216-24. doi:10.1080/01944366908977225

16 UNICEF. Minimum quality standards and indicators for community engagement. UNICEF, 2020.

17 Green G, Boaz AL, Stuttaford MC, eds. Public participation in health care: exploring the $\mathrm{CO}$ production of knowledge. Frontiers Media SA, 2020. doi:10.3389/978-2-88963-298-5

18 Hickey DG. The potential for coproduction to add value to research. Health Expect 2018;21:693-4 doi:10.1111/hex.12821

19 Hickey G, Brearley S, Coldham T, et al. Guidance on co-producing a research project. INVOLVE, 2018.

20 Abimbola S. The foreign gaze: authorship in academic global health. BMJ Glob Health 2019;4:e002068. doi:10.1136/ bmjgh-2019-002068

21 Campbell C, Gibbs A, Nair Y, Maimane S. Frustrated potential, false promise or complicated possibilities? Empowerment and participation amongst female health volunteers in South Africa. J Health Manag 2009;11:315-36. doi:10.1177/097206340901100204

22 Sultana F. Reflexivity, positionality and participatory ethics: negotiating fieldwork dilemmas in international research. ACME 2007;6:374-85.

23 Cahn E. No more throw-away people: the coproduction imperative. Essential Books Ltd, 2000.

24 Slutsky J, Tumilty E, Max C, et al. Patterns of public participation. J Health Organ Manag 2016;30:751 68. doi:10.1108/JHOM-03-2016-0037

25 Musesengwa R, Chimbari MJ. Experiences of community members and researchers on community engagement in an Ecohealth project in South Africa and Zimbabwe. BMC Med Ethics 2017;18:76. doi:10.1186/s12910-017-0236-3

26 Cornish F, Campbell C, Shukla A, Banerji R. From brothel to boardroom: prospects for community leadership of HIV interventions in the context of global funding practices. Health Place 2012;18:46874. doi:10.1016/i.healthplace.2011.08.018

27 Wilson P, Mathie E, Keenan J, et al. ReseArch with Patient and Public invOlvement: a RealisT evaluation - the RAPPORT study. Health Services and Delivery Research 2015;3. doi:10.3310/hsdr03380

28 Marsh V, Kamuya D, Rowa Y, Gikonyo C, Molyneux S. Beginning community engagement at a busy biomedical research programme: experiences from the KEMRI CGMRC-Wellcome Trust Research Programme, Kilifi, Kenya. Soc Sci Med 2008;67:72133. doi:10.1016/i.socscimed.2008.02.007

29 Clark T. 'We're over-researched here!': exploring accounts of research fatigue within qualitative research engagements. Sociology 2008;42:953-70. doi: $10.1177 / 0038038508094573$ 
30 Gbadegesin S, Wendler D. Protecting communities in health research from exploitation. Bioethics 2006;20:248-53. doi:10.1111/j.1467$8519.2006 .00501 . x$

31 Huang J, Lipman PD, Daniel Mullins C. Bridging the divide: building infrastructure to support communityacademic partnerships and improve capacity to conduct patient-centered outcomes research. Transl Behav Med 2017;7:773-82. doi:10.1007/s13142017-0487-z

32 Fredriksson M, Tritter JQ. Disentangling patient and public involvement in healthcare decisions: why the difference matters. Sociol Health Illn 2017;39:95111. doi:10.1111/1467-9566.12483

33 Staley K, Barron D. Learning as an outcome of involvement in research: what are the implications for practice, reporting and evaluation?Res Involv Engagem 2019;5:14. doi:10.1186/s40900-0190147-1

34 Street J, Stafinski T, Lopes E, Menon D. Defining the role of the public in Health Technology Assessment (HTA) and HTA-informed decision-making processes. Int J Technol Assess Health Care 2020;36:87-95. doi:10.1017/S0266462320000094

35 Gibbs L, Block K, MacDougall C, et al. Ethical use and impact of participatory approaches to research in post-disaster environments: an Australian bushfire case study. Biomed Res Int 2018;2018:5621609. doi:10.1155/2018/5621609

36 Michener L, CookJ, Ahmed SM, Yonas MA, Coyne-Beasley T, Aguilar-Gaxiola S. Aligning the goals of communityengaged research: why and how academic health centers can successfully engage with communities to improve health. Acad Med 2012;87:285-91. doi:10.1097/ACM.0b013e3182441680

37 Shucksmith MO. InterAction: How can academics and the third sector work together to influence policy and practice? Carnegie UK Trust, 2016

38 Owen D, Featherstone H, Leslie K. The state of play: public engagement with research in UK universities. 2016. htts://www.publicengagement.ac.uk/sites/ default/files/publication/state_of_play_final.pdf
39 AVAC. UNAIDS. Good participatory practice: guidelines for biomedical HIV prevention trials. 2nd ed. UNAIDS, 2011.

40 Chimbari MJ. Lessons from implementation of ecohealth projects in Southern Africa: a principal investigator's perspective. Acta Trop 2017;175:9-19. doi:10.1016/j.actatropica.2016.09.028

41 Powell KM, Takayoshi P. Accepting roles created for us: the ethics of reciprocity. Coll Compos Commun 2003;54:394-422. doi:10.2307/3594171

42 Maiter S, Simich L, Jacobson N, Wise J. Reciprocity: an ethic for community-based participatory action research. Action Res 2008;6:305-25 doi:10.1177/1476750307083720

43 UK Research and Innovation, Science and Technology Facilities Council. Sci-fi comic gives voice to young people during pandemic 2020. https://stfc.ukri.org/ news-events-and-publications/whats-happening/ sci-fi-comic-gives-voice-to-young-people-duringpandemic/.

44 O'Mara-Eves A, Brunton G, McDaid D, et al. Public Health Research. Community engagement to reduce inequalities in health: a systematic review. meta-analysis and economic analysis. NIHR Journals Library, 2013.

45 Jagosh J, Bush PL, Salsberg J, et al. A realist evaluation of community-based participatory research: partnership synergy, trust building and related ripple effects. BMC Public Health 2015;15:725. doi:10.1186/s12889-015-1949-1

46 Greenhalgh T, Hinton L, Finlay T, et al. Frameworks for supporting patient and public involvement in research: systematic review and co-design pilot. Health Expect 2019;22:785-801. doi:10.1111/ hex.12888

47 Farr M, Davies R, Davies P, Bagnall D, Brangan E, Andrews H. A map of resources for co-producing research in health and social care. Version 1.2. May 2020. National Institute for Health Research (NIHR) ARC West and People in Health West of England. University of Bristol and University of West of England, 2020
48 Bernheim RG. Public engagement in emergency preparedness and response: ethical perspectives in public health practice. In: Jennings B, Arras JD, Barrett DH, Ellis BA, eds. Emergency ethics: public health preparedness and response. Oxford University Press; 2016. https://oxfordmedicine.com/ view/10.1093/med/9780190270742.001.0001/ med-9780190270742-chapter-5

49 Ramsbottom A, O’Brien E, Ciotti L, Takacs I. Enablers and barriers to community engagement in public health emergency preparedness: a literature review. I Community Health 2018;43:412-20. doi:10.1007/ s10900-017-0415-7

50 Wright K. COVID-19, Research in global health emergencies. Nuffield Council on Bioethics. 2020. https://www.nuffieldbioethics.org/blog/were-all-inthis-together-what-does-this-mean-for-covid-19research

51 Pratt B, Hyder AA. Designing research funding schemes to promote global health equity: an exploration of current practice in health systems research. Dev World Bioeth 2018;18:76-90. doi:10.1111/dewb.12136

52 Surridge H, Green D, Hickey G, et al. Public reviewing with the National Institute for Health Research (NIHR) 2019. https://www.invo.org.uk/ resource-centre/learning-and-development/publicreviewing-with-the-national-institute-for-healthresearch-nihr/.

53 Terama E, Smallman M, Lock SJ, Johnson C, Austwick $M Z$. Beyond academia - interrogating research impact in the Research Excellence Framework. PLoS One 2016;11:e0168533. doi:10.1371/journal. pone. 0168533

54 Jaiswal J, LoSchiavo C, Perlman DC. Disinformation, misinformation and inequality-driven mistrust in the time of COVID-19: lessons unlearned from AIDS denialism. AIDS Behav 2020;24:2776-80. doi:10.1007/s10461-020-02925-y

Cite this as: $B M J$ 2021;372:n178

http://dx.doi.org/10.1136/bmj.n178 